\title{
Sorption of fluoride using chemically modified Moringa oleifera leaves
}

\author{
Shabnam Dan ${ }^{1} \cdot$ Amit Chattree $^{1}$
}

Received: 6 December 2016 / Accepted: 19 April 2018 / Published online: 7 May 2018

(c) The Author(s) 2018

\begin{abstract}
Contamination of drinking water due to fluoride is a severe health hazard problem. Excess of fluoride $(>1.5 \mathrm{mg} / \mathrm{L})$ in drinking water is harmful to human health. Various treatment technologies for removing fluoride from groundwater have been investigated. The present study showed that the leaves of Moringa oleifera, a herbal plant is an effective adsorbent for the removal of fluoride from aqueous solution. Acid treated Moringa oleifera leaves powder showed good adsorption capacity than alkali treated Moringa oleifera leaves powder. Batch sorptive defluoridation was conducted under the variable experimental condition such as $\mathrm{pH}$, contact time, adsorbent dose and initial fluoride ion concentration. Maximum defluoridation was achieved at $\mathrm{pH} 1$. The percentage of fluoride removal increases with adsorbent dose. The equilibrium sorption data were fitted into Langmuir, Freundlich and Temkin isotherms. Of the three adsorption isotherms, the $R^{2}$ value of Langmuir isotherm model was the highest. The maximum monolayer coverage $\left(Q_{\max }\right)$ from Langmuir isotherm model was determined to be $1.1441 \mathrm{mg} / \mathrm{g}$, the separation factor indicating a favorable sorption experiment is 0.035 . It was also discovered that the adsorption did not conform to the Freundlich adsorption isotherm. The heat of sorption process was estimated from Temkin Isotherm model to be $-0.042 \mathrm{~J} / \mathrm{mol}$ which vividly proved that the adsorption experiment followed a physical process.
\end{abstract}

Keywords Adsorption $\cdot$ Fluoride $\cdot$ Freundlich isotherm $\cdot$ Langmuir isotherm $\cdot$ Moringa oleifera $\cdot$ Temkin isotherm

\section{Introduction}

Water is most abundant and is an essential component of our life supporting system. Near about $97 \%$ of earth's surface is covered by water. But from the last few decades, these water resources are getting polluted by various natural and anthropogenic contaminants such as heavy metals, fluoride, arsenic, lead and mercury (Abu Bakar et al. 2016; Bashir et al. 2012). Among all the contaminants, fluoride contamination of water has now become a major issue in most of the parts of the world because of its toxic effects. Fluoride is well recognized as an element of public health concern. Fluoride is present universally in almost every water (higher concentrations are found in ground water), earth crust, many minerals, rocks, etc. It is also present in most of our everyday needs, viz. toothpastes, drugs, cosmetics, chewing gums, mouthwashes, and so forth (Bashir et al. 2012; Rout et al. 2015). Though a small amount

Shabnam Dan

shabnamjasmine@gmail.com

Amit Chattree

amit.chattree@shiats.edu.in

1 Department of Chemistry, Sam Higginbottom Institute of Agriculture, Science and Technology, Allahabad, India of it is beneficial for human health for preventing dental carries, it is very harmful when present in excess. Maximum permissible limit of fluoride in drinking water has been set as $1.5 \mathrm{mg} / \mathrm{L}$ by many regulatory authorities such as WHO, US EPA, CPCB and so forth (Bashir et al. 2015; Bell and Ludwig 1970; Kanaujia et al. 2015; Singh 2017). The high fluoride levels in drinking water and its impacts on human health have increased the importance of defluoridation studies (Chidambaram et al. 2004; Singh 2017). The magnitude of the problem is sinking in, and efforts are being made towards defluoridation of drinking water, combating the debilating fluorosis and taking steps to prevent and control the disease (Karthikeyan and Ilango 2007). Chemical coagulants like Aluminum sulphate (alum), $\mathrm{FeCl}_{2}$ are used in the Municipal drinking water treatment plant for the purification process. This excess use of an amount of chemical coagulants can affect human health, e.g., Aluminum has also been indicated to be a causative agent in neurological diseases such as pre-senile dementia (Muyibi and Evison 1995). The conventional method of fluoride removal includes: ion-exchange, reverse osmosis, and adsorption (Popat et al. 1994). Adsorption processes using natural adsorbents or agricultural waste products are becoming the new alternatives for the removal of fluoride from aqueous solution as they are 
cheap, simple, sludge-free, regenerable, environment friendly, involve small initial cost, and minimal chemical use (Saka and Sahin 2011).

The use of Moringa oleifera has an added advantage over the chemical treatment of water because it is biological and has been reported as edible.

\section{Experimental methods}

\section{Collection and preparation of adsorbent and adsorbate}

Moringa oleifera leaves were used as adsorbent and were collected from local trees and were washed with water many times to remove dirt and then sun dried for 3 days. The dried sample was then ground to powder using a pestle and mortar, the dried sample powder was then sieved to select the particle size of $350 \mu \mathrm{m}$ and was then used as an adsorbent. $40 \mathrm{~g}$ of the powder sample was added to $400 \mathrm{~mL}$ of $1 \mathrm{~N} \mathrm{HNO}_{3}$ for acid treatment, and $40 \mathrm{~g}$ of the powder sample was added to $0.5 \mathrm{~N} \mathrm{NaOH}$ for alkali treatment. This modified procedure is in accordance with the reported work of Parlikar and Mokashi (2013). The mixture was boiled for about $20 \mathrm{~min}$ on a sand bath. Washing of the powder sample was carried out using distilled water until the maximum color was removed and clear water was obtained. Finally, it was dried again in an oven at $50{ }^{\circ} \mathrm{C}$ for $6 \mathrm{~h}$.

The preparation of adsorbate was carried out by preparing a standard solution of $2 \mathrm{ppm}$ fluoride. It was prepared by dissolving $2 \mathrm{mg}$ of anhydrous sodium fluoride in $1000 \mathrm{~mL}$ of distilled water.

\section{Preparation of the reagent}

The SPADNS solution, $0.003721 \mathrm{M}$ was prepared by dissolving $0.4750 \mathrm{~g}$ of SPADNS in $250 \mathrm{~mL}$ deionized water. The Zirconyl chloride acid solution, $0.0375 \mathrm{M}$ was by prepared by dissolving $0.0665 \mathrm{~g}$ of $\mathrm{ZrOCl}_{2} \cdot 8 \mathrm{H}_{2} \mathrm{O}$ in $25 \mathrm{~mL}$ of deionized water. Then $25 \mathrm{~mL}$ of $\mathrm{HCl}$ was added, and deionized water was added until the total volume of the solution was $250 \mathrm{~mL}$. The concentration of zirconyl acid-SPADNS reagent was prepared by mixing the two solutions in the ratio of $1: 1$. This reagent was further diluted.

\section{Sorption experiment}

Synthetic fluoride bearing water sample having initial fluoride ion concentration of $2 \mathrm{mg} / \mathrm{L}$ was used. This fluoride solution was filtered using Whatman's filter paper no. 41 to this filtrate, SPADNS and zirconyl acid solution of $5 \mathrm{~mL}$ each was used. The sample was checked for fluoride detection using spectrophotometer at wavelength $570 \mathrm{~nm}$.
The fluoride removal studies by adsorption were conducted in $250 \mathrm{~mL}$ conical flask using $100 \mathrm{~mL}$ of synthetic water sample. To these conical flasks acid and alkali treated (activated) adsorbent was added and after giving a required contact time of 150 min the contents of the flask were then filtered using Whatman's filter paper no. 41. The filtrate was used for fluoride ion estimation using the SPADNS method. The fluoride content in the filtrate was determined by UV-visible spectrophotometer. The values of percent fluoride removal by adsorbent were calculated using the following relation (Bashir et al. 2015).

Removal $\%=\frac{C_{0}-C_{i}}{C_{0}} \times 100$

where, $C_{0}$ is initial fluoride ion concentration, and $C_{\mathrm{i}}$ is the final fluoride ion concentration.

\section{Langmuir isotherm}

The Langmuir isotherm is valid for monolayer adsorption onto a surface containing a finite number of identical sites. The model assumes uniform energies of adsorption onto the surface and no transmigration of adsorbate in the plane of the surface (Foo and Hameed 2010). The linear form of Langmuir isotherm model is described as:

$\frac{C_{e}}{q_{e}}=\frac{1}{q_{\max K_{L}}}+\frac{1}{q_{\max }} c_{e}$

where,

$q_{\max }=$ The monolayer adsorption capacity of the adsorbent $(\mathrm{mg} / \mathrm{g})$.

$K_{\mathrm{L}}=$ The Langmuir adsorption constant (L/mg).

$C_{\mathrm{e}}=$ Equilibrium concentration of the solution in $(\mathrm{mg} / \mathrm{L})$.

$q_{\mathrm{e}}=$ Amount adsorbed per unit weight of adsorbent (mg/g).

Further, the essential characteristics of the Langmuir isotherm can be described by a separation factor, $R_{\mathrm{L}}$, which is defined by the following equation,

$R_{L}=\left[1 /\left(1+b C_{i}\right)\right]$.

where $C_{i}$ is the initial concentration of the fluoride solution and $b$ is the Langmuir constant related to the energy of adsorption $\left(\mathrm{L} \mathrm{mg}^{-1}\right) . R_{\mathrm{L}}$ value indicates the adsorption nature to be either unfavorable if $R_{\mathrm{L}}>1$ ), linear if $R_{\mathrm{L}}=1$, favorable if $0<R_{\mathrm{L}}<1$ and irreversible if $R_{\mathrm{L}}=0$ (Foo and Hameed 2010).

\section{Freundlich isotherm}

It is applicable to both monolayer and multilayer adsorption and is based on assumption that adsorbate adsorbs onto heterogeneous surfaces of an adsorbent (Bashir et al. 2017; Foo 
and Hameed 2010). The linear form of Freundlich equation is expressed as:

$q_{\mathrm{e}}=K_{\mathrm{f}} C_{\mathrm{e}}^{1 / n}$

where,

$q_{\mathrm{e}}=$ Amount adsorbed per unit weight of adsorbent $(\mathrm{mg} / \mathrm{g})$.

$C_{\mathrm{e}}=$ Equilibrium concentration of the solution in $(\mathrm{mg} / \mathrm{L})$.

$K_{\mathrm{f}}$ and $n$ are Freundlich Isotherms constants which is a measure of adsorption capacity or fundamental effectiveness of the adsorbent. $K_{\mathrm{F}}$ and $n$ can be determined from the linear plot of $\log q_{\mathrm{e}}$ verses $\log C_{\mathrm{e}}$ as shown in the equation. The adsorption process is said to be favorable when the value of ' $n$ ' satisfies the condition $1<n<10$ which indicated favorability of adsorption and the degree of heterogeneity, otherwise it is unfavorable (Foo and Hameed 2010).

\section{Temkin isotherm}

This isotherm contains a factor that explicitly takes into account of adsorbent-adsorbate interactions. The model assumes that heat of adsorption (function of temperature) of all molecules in the layer would decrease linearly rather than logarithmic with coverage. As implied in the equation, its derivation is characterized by a uniform distribution of binding energies (up to some maximum binding energy) was carried out by plotting the quantity sorbed $q_{\mathrm{e}}$ against $\ln C_{\mathrm{e}}$ and the constants were determined from the slope and intercept (Foo and Hameed 2010). The model is given by the following equation:

$q_{\mathrm{e}}=B \ln A_{\mathrm{T}}+B \ln C_{e}$.

$A_{\mathrm{T}}=$ Temkin isotherm equilibrium binding constant $(\mathrm{L} / \mathrm{g})$.

$b_{\mathrm{T}}=$ Temkin isotherm constant.

$R=$ universal gas constant $(8.314 \mathrm{~J} / \mathrm{mol} / \mathrm{K})$.

$T=$ Temperature.

$B=$ Constant related to heat of sorption $(\mathrm{J} / \mathrm{mol})$.

\section{Chemical kinetics}

The experimental data are analyzed to observe the appropriate kinetic model followed by adsorption process including mass transfer and chemical reactions (Bashir et al. 2017). Pseudo-first-order and pseudo-second-order kinetic models are used to describe the kinetics of adsorption. The integrated form of Lagergren first-order kinetic model is represented by the equation given below:

$\log q_{e}-q_{t}=\log q_{e}-\frac{k 1}{2.303} t$

where $k_{1}$ is the rate constant of first-order adsorption $(1 / \mathrm{min}) ; q_{\mathrm{e}}$ is the amount of dye adsorbed in $\mathrm{mg} / \mathrm{g}$ at equilibrium; and $q_{t}$ is the amount of dye adsorbed in $\mathrm{mg} / \mathrm{g}$ at any time $t$.

The linear form of pseudo-second-order kinetic model rate equation is expressed as:

$t / q t=1 / k_{2} q_{e}^{2}+\left(1 / q_{e}\right) t$

where $k_{2}$ is the rate constant of second-order adsorption (g/ mg-min) depends on the sorption capacity of the solid phase. The initial sorption rate, $h(\mathrm{mg} / \mathrm{g}$-min), is also calculated with the help of second-order kinetic model by the following expression:

$h=k_{2} q_{e}^{2}$.

\section{Results and discussions}

Understanding of adsorption technique is possible with knowledge of the optimal conditions, which would herald a better design and modeling process. Thus, the effect of some major parameters such as $\mathrm{pH}$, contact time, dose of adsorbent and initial concentration of fluoride ions uptake on adsorbent materials were investigated from a kinetic viewpoint. Adsorption studies were performed by batch technique to obtain the equilibrium data. The experimental data from batch experiment were analyzed using adsorption isotherm equations (Langmuir, Freundlich, and Temkin), in which linear regression analysis was used to evaluate whether the theoretical models have better or worse fit for the experimental data.

\section{Effect of pH on defluoridation}

The $\mathrm{pH}$ of the aqueous solution is a controlling factor in the adsorption process (Bashir et al. 2015). The experiments were carried out for acid treated and alkali treated Moringa oleifera leaves powder for determining optimum $\mathrm{pH}$. The $\mathrm{pH}$ was varied from 1 to 10 for acid treated Moringa oleifera leaves powder and 2-10 for alkali treated Moringa oleifera leaves powder. The adsorbent having $350 \mu \mathrm{m}$ size, acid treated as well as alkali treated, was used to determine optimal $\mathrm{pH}$ at which the adsorption was maximum. For these experiments, initial fluoride ion concentration was $2 \mathrm{mg} / \mathrm{L}$, with an adsorbent dose of $2.5 \mathrm{~g} / \mathrm{L}$ and contact time of $150 \mathrm{~min}$. As shown in Table 1, the acid treated adsorbent showed the maximum removal efficiency $83 \%$ at $\mathrm{pH} 1$. Whereas in case of alkali treated adsorbent the maximum removal efficiency was $85 \%$ at $\mathrm{pH}$ 10. Similar observations have been reported by (Parlikar and Mokashi 2013). 
Table 1 Effect of $\mathrm{pH}$ on sorption of fluoride

\begin{tabular}{|c|c|c|c|c|c|}
\hline \multirow[t]{2}{*}{ S. no } & \multirow[t]{2}{*}{$\mathrm{pH}$} & \multicolumn{2}{|c|}{ Acid treated powder } & \multicolumn{2}{|c|}{ Alkali treated powder } \\
\hline & & $\begin{array}{l}\text { Absorbance } \\
(A)\end{array}$ & $\%$ Removal & $\begin{array}{l}\text { Absorbance } \\
\text { (A) }\end{array}$ & $\%$ Removal \\
\hline 1. & 1 & 0.020 & 83 & & \\
\hline 2. & 2 & 0.023 & 81 & 0.055 & 54 \\
\hline 3. & 4 & 0.031 & 74 & 0.040 & 67 \\
\hline 4. & 6 & 0.044 & 63 & 0.030 & 75 \\
\hline 5. & 8 & 0.057 & 53 & 0.021 & 82 \\
\hline 6. & 10 & 0.059 & 51 & 0.018 & 85 \\
\hline
\end{tabular}

\section{Effect of contact time on defluoridation}

The adsorbent dose of $2.5 \mathrm{~g} / \mathrm{L}$ was taken and kept constant throughout the experimental work. The contact time was varied from 0.5 to $2.5 \mathrm{~h}$ for acid treated as well as alkali treated Moringa oleifera leaves powder of particle size $350 \mu \mathrm{m}$. The experimental study was carried out to determine optimal contact time using acid and alkali treated adsorbents with same particle size. The $\mathrm{pH}$ was 8 and dose was $2.5 \mathrm{~g} / \mathrm{L}$ for the study. As depicted in Table 2 in case of alkali treated adsorbent it is found that the removal fluoride ion increased with increase in contact time but after sometime it approaches a constant value, denoting attainment of equilibrium. Whereas, in case of acid treated adsorbent the amount of percentage removal of fluoride ion increased with increase in time, as well as the maximum percentage removal (98\%) was obtained at $150 \mathrm{~min}$. Similar results were reported by Kosari and Sepehrian (2017).

\section{Effect of adsorbent dose on defluoridation}

The response of adsorbent dose on the removal of fluoride is presented in Table 3. In case of alkali treated powder, the observations reveal that an increase in the adsorption occurs with the corresponding increase in the amount of adsorbent. The increase in the removal efficiency with simultaneous increase in adsorbent dose is due to the increase in quantity, and hence more active sites were available for the adsorption of fluoride. The results showed that the alkali treated Moringa oleifera leaves powder was efficient for $95 \%$ removal of fluoride ions at the lowest dose of $100 \mathrm{mg} / \mathrm{L}$ and $98 \%$ at a maximum dose of $400 \mathrm{mg} / \mathrm{L}$, respectively, at room temperature. This finding is supported by (Tembhurkar and Dongre 2009).
Table 2 Effect of contact time on defluoridation

Table 3 Effect of adsorbent dose on defluoridation

\begin{tabular}{lclllll}
\hline S. no & Time $(\mathrm{min})$ & \multicolumn{2}{l}{ Acid treated powder } & & \multicolumn{2}{l}{ Alkali treated powder } \\
& & Absorbance $(A)$ & \% Removal & & Absorbance $(A)$ & \% Removal \\
\hline 1. & 30 & 0.015 & 87 & 0.015 & 87 \\
2. & 60 & 0.013 & 89 & 0.011 & 90 \\
3. & 90 & 0.012 & 90 & 0.010 & 91 \\
4. & 120 & 0.006 & 95 & & 0.006 & 95 \\
5. & 150 & 0.002 & 98 & & 0.005 & 95 \\
\hline
\end{tabular}

\begin{tabular}{|c|c|c|c|c|c|}
\hline \multirow[t]{2}{*}{ S. no } & \multirow{2}{*}{$\begin{array}{l}\text { Adsorbent dose } \\
(\mathrm{mg})\end{array}$} & \multicolumn{2}{|c|}{ Acid treated powder } & \multicolumn{2}{|c|}{ Alkali treated powder } \\
\hline & & Absorbance $(A)$ & $\%$ Removal & Absorbance $(A)$ & $\%$ Removal \\
\hline 1. & 100 & 0.003 & 97 & 0.006 & 95 \\
\hline 2. & 200 & 0.006 & 95 & 0.004 & 96 \\
\hline 3. & 300 & 0.008 & 93 & 0.003 & 97 \\
\hline 4. & 400 & 0.010 & 91 & 0.002 & 98 \\
\hline
\end{tabular}

Table 4 Effect of fluoride ion concentration on defluoridation

\begin{tabular}{lllllll}
\hline S. no & $\begin{array}{l}\text { Fluoride ion con- } \\
\text { centration }(\mathrm{mg})\end{array}$ & \multicolumn{2}{l}{ Acid treated powder } & & \multicolumn{2}{l}{ Alkali treated powder } \\
& & Absorbance $(A)$ & \% Removal & & Absorbance $(A)$ & \% Removal \\
\hline 1. & 0.5 & 0.017 & 86 & 0.023 & 81 \\
2. & 1 & 0.010 & 91 & 0.020 & 83 \\
3. & 1.5 & 0.007 & 94 & 0.013 & 89 \\
4. & 2 & 0.002 & 98 & & 0.009 & 92 \\
\hline
\end{tabular}




\section{Effect of initial fluoride ion concentration}

Studies on the effect of initial fluoride concentration were conducted by varying it from 0.5 to $2 \mathrm{mg} / \mathrm{L}$ keeping adsorbent dose of $2.5 \mathrm{~g} / \mathrm{L}, \mathrm{pH}$ of 8 , and contact time of $150 \mathrm{~min}$.

The response of different fluoride ion concentration on the removal of fluoride is presented in Table 4. For alkali as well as acid treated powder, the observations reveal that with the increase in fluoride ion concentration the $\%$ removal of fluoride also increases. With increase in initial concentration of fluoride the driving force for transport of fluoride from the bulk to the surface of adsorbent increases, which results more adsorption of fluoride per unit mass of adsorbent. This finding is supported by (Dwivedi et al. 2014).

\section{Adsorption isotherms}

In this study, adsorption isotherm study was carried out on three isotherm models: Langmuir, Freundlich and Temkin. The applicability of isotherm models to the adsorption study done was compared by observing the correlation coefficients, $R^{2}$ value. Adsorption isotherm helps in determining the feasibility of acid and alkali treated Moringa oleifera leaves powder for treating fluoride ion in water. Langmuir, Freundlich and Temkin isotherms were plotted to provide deep insight to the adsorption of fluoride ion on Moringa oleifera leaves powder.

From Table 5, it is clear that acid and alkali treated adsorbent responded good behavior with all three types of isotherm models but Langmuir's isotherm fitted best with them which is also well explained and depicted in Fig. 1a and b by the good regression coefficient of 0.97 and 0.88 , respectively. The Langmuir's model described the monolayer sorption nature of the adsorbent.

Table 5 shows adsorption of fluoride on the adsorbents having a range of values of linear regression coefficient, $R^{2}$ (0.885-0.993) as illustrated in Fig. 2a and b, demonstrating that the experimental data fitted well with the Freundlich isotherm equation. Moreover, it was reported that the Freundlich isotherm constant can be used to explore the favorability of adsorption process (Foo and Hameed 2010). As observed in Table 5, the value of $\mathrm{n}$ for the adsorption of fluoride on acid treated Moringa oleifera leaves is situated outside the range of 1-10 indicating unfavorable adsorption process. Whereas, the value of $\mathrm{n}$ for the adsorption of fluoride on alkali treated Moringa oleifera leaves is situated in the range of 1-10 indicating favorable adsorption process.

It is well defined from the Table 5 and so is shown in Fig. 3a and b, that Temkin isotherm data fitted quite well. The values of $R^{2}$ are positioned within 0.983-0.986, which gave a close fit to the adsorption of fluoride on acid and alkali treated Moringa oleifera leaves powder. Furthermore, it can also be observed in Table 5, that the heat of adsorption of fluoride on Moringa oleifera leaves was restricted within $-59,979$ to $26,241 \mathrm{~kJ} / \mathrm{mol}$.

In the present study, the value of $R_{\mathrm{L}}$ is greater than $0-1$ for acid and alkali treated adsorbent indicating that Langmuir isotherm is favorable (Bashir et al. 2015; Foo and Hameed 2010). While the value of $\mathrm{n}$ is greater than 10 for acid treated adsorbent indicating unfavorable adsorption process whereas for alkali treated adsorbent it is favorable.

Through the adsorption equilibrium study employing Langmuir, Freundlich and Temkin isotherms models, the
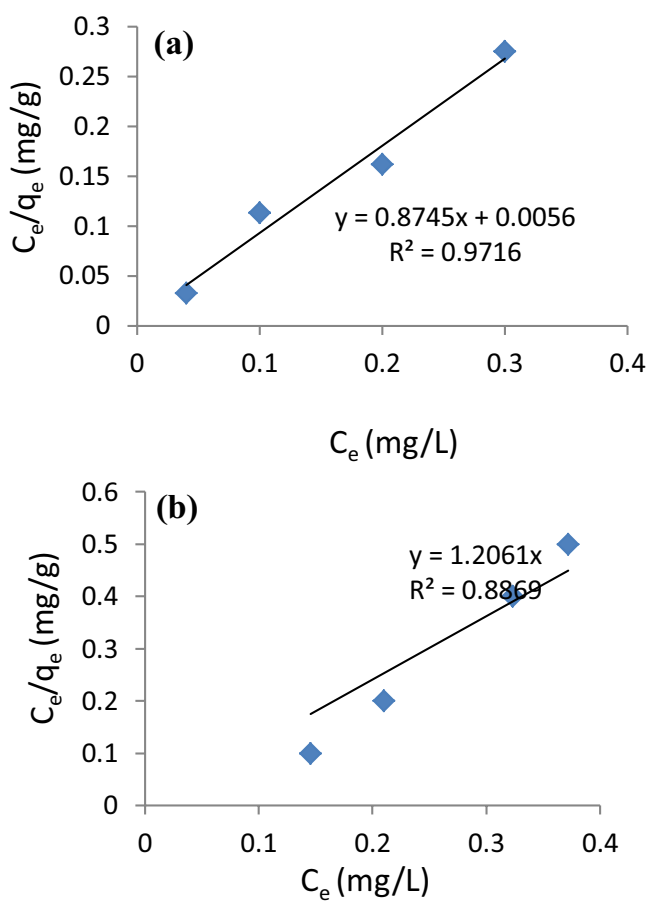

Fig. 1 a Langmuir Isotherm for effect of initial fluoride ion concentration on defluoridation (Acid treated Moringa oleifera leaves powder). b Langmuir Isotherm for effect of initial fluoride ion concentration on defluoridation (Alkali treated Moringa oleifera leaves powder)

Table 5 Langmuir, Freundlich and Temkin equation values for adsorption of fluoride with respect to initial fluoride ion concentration

\begin{tabular}{|c|c|c|c|c|c|c|c|c|c|c|}
\hline \multirow[t]{2}{*}{ Adsorbents } & \multicolumn{4}{|l|}{ Langmuir } & \multicolumn{3}{|l|}{ Freundlich } & \multicolumn{3}{|l|}{ Temkin } \\
\hline & $Q_{\max }(\mathrm{mg} / \mathrm{g})$ & $R_{\mathrm{L}}$ & $K_{\mathrm{L}}(\mathrm{L} / \mathrm{mg})$ & $R^{2}$ & $K_{\mathrm{f}}(\mathrm{mg} / \mathrm{g})$ & Value of ' $n$ ' & $R^{2}$ & $B(\mathrm{~J} / \mathrm{mol})$ & $A_{\mathrm{T}}(\mathrm{L} / \mathrm{g})$ & $R^{2}$ \\
\hline Acid treated & 1.1441 & 0.003589 & 138.79 & 0.971 & 0.6546 & 17.543 & 0.885 & -0.042 & $1.951 \times 10^{-7}$ & 0.897 \\
\hline Alkali treated & 0.8340 & 0.000833 & 0.002 & 0.884 & 0.5727 & 7.2463 & 0.983 & -0.096 & 0.0029 & 0.986 \\
\hline
\end{tabular}




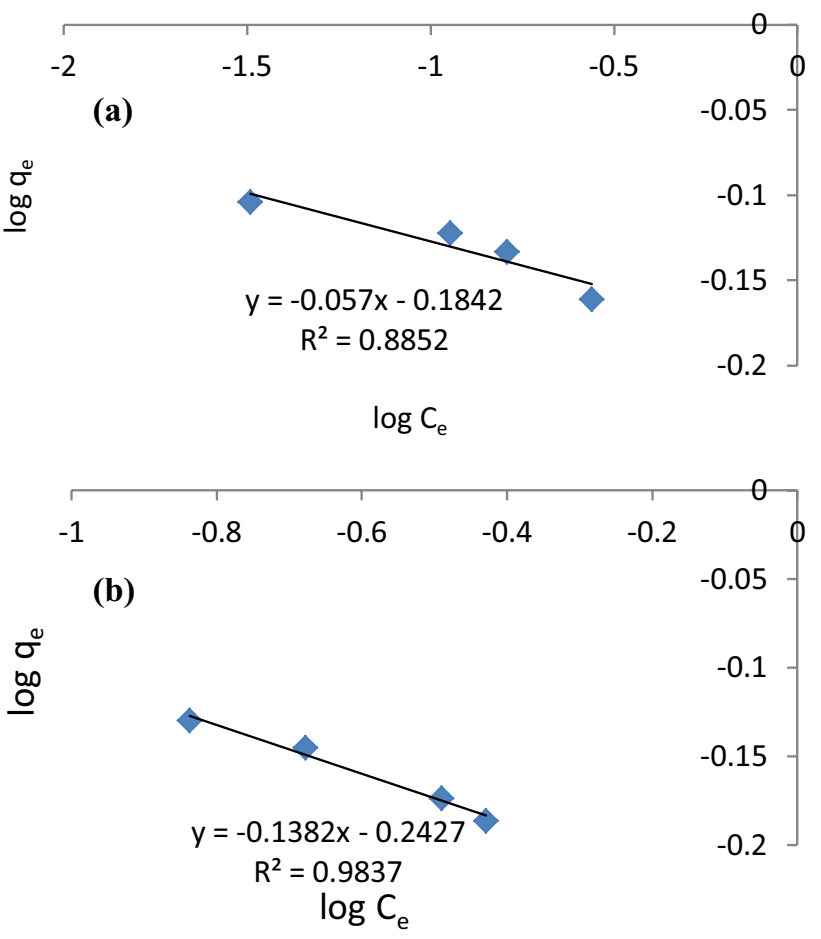

Fig. 2 a Freundlich Isotherm for effect of initial fluoride ion concentration on defluoridation (Acid treated Moringa oleifera leaves powder). b Freundlich Isotherm for effect of initial fluoride ion concentration on defluoridation (Alkali treated Moringa oleifera leaves powder)

maximum adsorption capacity was determined where the adsorption of fluoride with acid treated Moringa oleifera leaves powder was $1.1441 \mathrm{mg} / \mathrm{g}$ and with alkali treated Moringa oleifera leaves powder was $0.8340 \mathrm{mg} / \mathrm{g}$. It is concluded by referring to the data obtained that the acid treated Moringa oleifera leaves powder was more efficient in removing fluoride than alkali treated Moringa oleifera leaves powder.

\section{Mechanism of adsorption}

The acid treated adsorbent contains the functional groups such as $-\mathrm{OH}, \mathrm{C}=\mathrm{O}$ and secondary amine group that is involved in adsorption process (Abu Bakar et al. 2016; Bello et al. 2015). Whereas, in case of alkali treated adsorbent functional groups that are involved in the process of adsorption are $-\mathrm{OH}$ and $\mathrm{C}=\mathrm{O}$ (Bello et al. 2015). Protonation of heteroatoms took place due to lone pairs of electrons. Thus, heteroatoms such as $\mathrm{O}$ and $\mathrm{N}$ developed the positive charge.

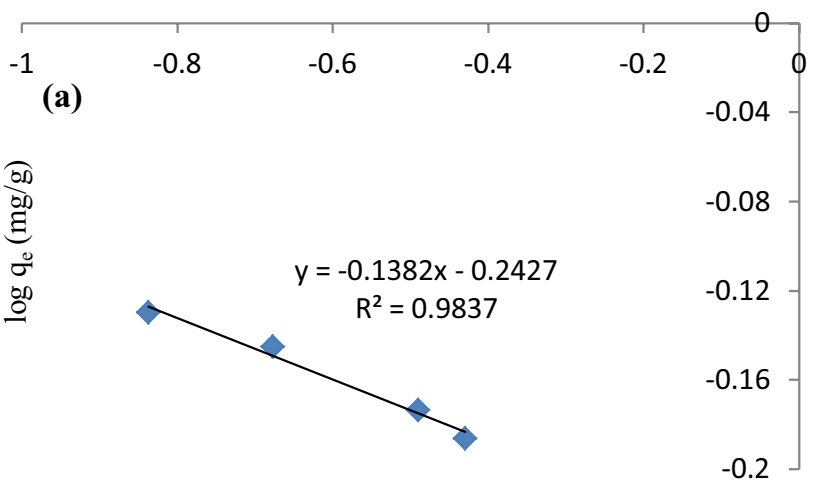

$\ln \mathrm{C}_{\mathrm{e}}(\mathrm{mg} / \mathrm{L})$

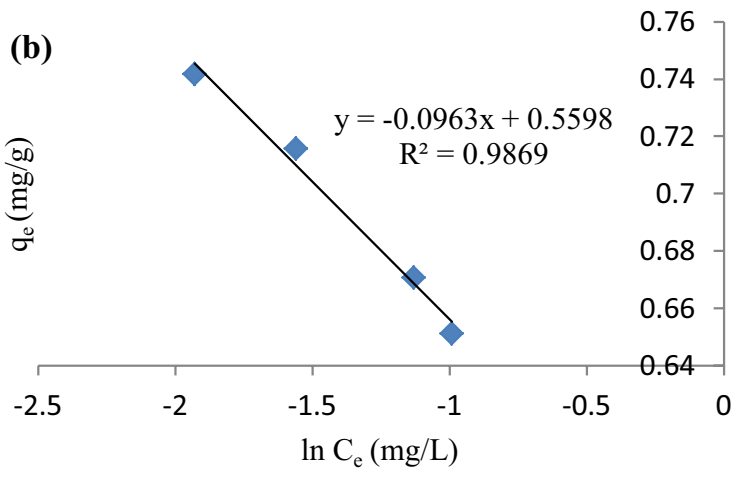

Fig. 3 a Temkin Isotherm for effect of initial fluoride ion concentration on defluoridation (Acid treated Moringa oleifera leaves powder). b Temkin Isotherm for effect of initial fluoride ion concentration on defluoridation (Alkali treated Moringa oleifera leaves powder)

These positive charges on heteroatoms are responsible for the adsorption of fluoride ions from aqueous solution.

$$
\begin{aligned}
& \mathrm{S}-\mathrm{OH}+\mathrm{H}^{+} \rightarrow \mathrm{S}-\mathrm{OH}_{2}^{+} \text {(protonation) } \\
& {\left[+\mathrm{F}^{-} \text {(Electrostatic attraction) }\right]} \\
& \mathrm{S}-\mathrm{C}=\mathrm{O}+\mathrm{H}^{+} \rightarrow \mathrm{S}-\mathrm{C}=\mathrm{OH}^{+} \text {(protonation) } \\
& {\left[+\mathrm{F}^{-}(\text {Electrostatic attraction) }\right.} \\
& \mathrm{S}-\mathrm{HN}-\mathrm{R}_{2}+\mathrm{H}^{+} \rightarrow \mathrm{S}-\mathrm{H}_{2} \mathrm{~N}^{+}-\mathrm{R}_{2} \text { (protonation) } \\
& {\left[+\mathrm{F}^{-} \text {(Electrostatic attraction) }\right]}
\end{aligned}
$$

Electrostatic physisorption between ions and dipole (second strongest among the physical bonds). Here, Electrostatic attraction between positive poles of partial polar bonds of $\mathrm{OH}, \mathrm{NH}$ and $\mathrm{CO}$ groups of adsorbent and anionic fluoride ion took place. 
Table 6 Kinetics of pseudo-first-order and pseudo second order of the two adsorbents studied

\begin{tabular}{|c|c|c|c|c|c|c|c|c|}
\hline \multirow[t]{2}{*}{ Adsorbents } & \multicolumn{3}{|c|}{ Pseudo first order } & \multicolumn{4}{|c|}{ Pseudo second order } & \multirow[t]{2}{*}{$Q_{\mathrm{e}}(\exp )(\mathrm{mg} / \mathrm{g})$} \\
\hline & $Q_{\mathrm{e}(\mathrm{cal})}(\mathrm{mg} / \mathrm{g})$ & $K_{1}(\mathrm{~L} / \mathrm{min})$ & $R^{2}$ & $Q_{\mathrm{e}(\mathrm{cal})}(\mathrm{mg} / \mathrm{g})$ & $K_{2}(\mathrm{~g} / \mathrm{mg}-\mathrm{min})$ & $R^{2}$ & $H$ & \\
\hline Acid treated & 4.89 & 0.88 & 0.835 & 1.23 & 0.093 & 0.996 & 0.142 & 1.20 \\
\hline Alkali treated & 1.65 & 1.70 & 0.867 & 1.27 & 0.135 & 0.999 & 0.219 & 1.20 \\
\hline
\end{tabular}

$$
\begin{gathered}
\mathrm{S}-\mathrm{O}^{-\delta}-\mathrm{H}^{+\delta}+\mathrm{F}^{-} \rightarrow \mathrm{S}-\mathrm{O}^{-\delta}-\mathrm{H}^{+\delta} \ldots \ldots . \mathrm{F}^{-} \\
\mathrm{S}-\mathrm{N}^{-\delta}-\mathrm{H}^{+\delta}+\mathrm{F}-\rightarrow \mathrm{S}-\mathrm{N}^{-\delta}-\mathrm{H}^{+\delta} \ldots . \mathrm{F}^{-} \\
\mathrm{S}-\mathrm{C}^{+\delta}+\mathrm{F}^{-} \rightarrow \underset{\mathrm{O}^{-\delta}}{\mathrm{S}-\mathrm{C}^{+\delta} \ldots . . \mathrm{F}^{-}} \\
\|^{-\delta}
\end{gathered}
$$

\section{Chemical kinetics}

A larger adsorption rate constant $k_{1}$ usually represents a quicker adsorption rate. Larger the $k_{2}$ values slower the rate of adsorption. The correlation coefficients of pseudo first order are less than those of pseudo-second-order reaction (Tables 6). This indicates that kinetic data for adsorption of fluoride by the acid and alkali treated adsorbents prepared from Moringa oleifera leaves are better fitted to pseudo-second-order rate equation than to pseudo first-order rate equation. The values of the pseudo first-order rate constant $\left(k_{1}\right)$ for both the adsorbent are not close to each other compared to those of pseudo-second-order rate constant $\left(k_{2}\right)$. Moreover, the calculated values of qe for both the adsorbents from second-order kinetic equation are found to be agreed well with the experimental values of $q_{\mathrm{e}}$. Therefore, it is concluded that the adsorption of fluoride by these adsorbents follows the pseudo-second-order reaction kinetics. This result is in agreement with the results obtained for the defluoridation using banana peel and coffee husk (Getachew et al. 2014).

\section{Conclusion}

The correlation coefficient, $R^{2}$ value for both the adsorbents indicated that all three Isotherms (Langmuir, Freundlich and Temkin) showed a good fit to the experimental data. The Langmuir Isotherm was slightly better than Freundlich and Temkin Isotherm. The process of adsorption also follows pseudo-second-order rate equation in both cases. It is concluded by referring to the data obtained that the acid treated Moringa oleifera leaves powder was more efficient in removing fluoride than alkali treated Moringa oleifera leaves powder.
Open Access This article is distributed under the terms of the Creative Commons Attribution 4.0 International License (http://creativeco mmons.org/licenses/by/4.0/), which permits unrestricted use, distribution, and reproduction in any medium, provided you give appropriate credit to the original author(s) and the source, provide a link to the Creative Commons license, and indicate if changes were made.

\section{References}

Abu Bakar A, Koay Y, Ching Y, Abdullah L, Choong T, Alkhatib M et al (2016) Removal of fluoride using quaternized palm kernel shell as adsorbents: equilibrium isotherms and kinetics studies. Bioresources 11:4485-4511. https://doi.org/10.15376/biore s.11.2.4485-4511

Bashir MT, Bashir A, Rasheed M (2012) Fluorides in the groundwater of Punjab. Pak J Med Health Sci 6:132-135

Bashir MT, Salmiaton A, Idris A, Harun R, Nourouzi MM (2015) Fluoride removal by chemical modification of palm kernel shell-based adsorbent: a novel agricultural waste utilization approach. Asian J Microbiol Biotech Environ Sci 17:533-542

Bashir MT, Salmiaton A, Idris A, Harun R (2017) Kinetic and thermodynamic study of nitrate adsorption from aqueous solution by lignocellulose-based anion resins. Desalin Water Treat 62:449-456

Bell MC, Ludwig TG (1970) The supply of fluoride to man: ingestion from water. Fluorides and Human Health. World Health Organization, Geneva, p 59 (WHO Monograph Series)

Bello SO, Adegoke AK, Akinyunni O (2015) Preparation and characterization of a novel adsorbent from Moringa oleifera leaf. Appl Water Sci 7:1295-1305. https://doi.org/10.1007/s1320 1-015-0345-4

Chidambaram S, Ramanathan A, Vasudevan S (2004) Fluoride removal studies in water using natural materials: technical note. Water SA 29:339-343. https://doi.org/10.4314/wsa.v29i3.4936

Dwivedi S, Mondal P, Majumder CB (2014) Removal of fluoride using citrus limettain batch reactor: kinetics and equilibrium studies. Res J Chem Sci 4:50-58

Foo K, Hameed B (2010) Insights into the modeling of adsorption isotherm systems. Chem Eng J 156:2-10. https://doi. org/10.1016/j.cej.2009.09.013

Getachew T, Hussen A, Rao V (2014) Defluoridation of water by activated carbon prepared from banana (Musa paradisiaca) peel and coffee (Coffea arabica) husk. Int J Environ Sci Technol 12(6):1857-1866. https://doi.org/10.1007/s13762-014-0545-8

Kanaujia S, Singh B, Singh S (2015) Comparative Study on removal of fluoride from groundwater by natural and modified bagasse carbon of sugarcane. Int Res J Pure Appl Chem 8:147-156. https://doi.org/10.9734/irjpac/2015/17965

Karthikeyan G, Ilango SS (2007) Fluoride sorption using Moringa indica based activated carbon. Iran J Environ Health Sci Eng 6:21-28

Kosari M, Sepehrian H (2017) Fluoride ions removal using yttrium alginate biocomposite from an aqueous solution. Int J Eng. https ://doi.org/10.5829/idosi.ije.2017.30.01a.01

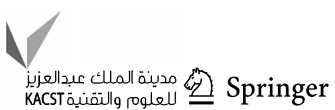


Muyibi S, Evison L (1995) Moringa oleifera seeds for softening hardwater. Water Res 29:1099-1104. https://doi.org/10.1016/00431354(94)00250-b

Parlikar AS, Mokashi SS (2013) Defluoridation of water by moringa oleifera-a natural adsorbent. Int J Eng Sci Innov Technol $2: 245-252$

Popat K, Anand P, Dasare B (1994) Selective removal of fluoride ions from water by the aluminium form of the aminomethylphosphonic acid-type ion exchanger. React Polym 23:23-32. https://doi.org/10.1016/0923-1137(94)90107-4

Rout T, Verma R, Dennis R, Banerjee S (2015) Study the removal of fluoride from aqueous medium by using nano-composites. J Encapsul Ads Sci 05:38-52. https://doi.org/10.4236/ jeas.2015.51004

Saka C, Sahin Ö (2011) Removal of methylene blue from aqueous solutions by using cold plasma- and formaldehyde-treated onion skins. Coloration Technol 127:246-255. https://doi.org/10.111 1/j.1478-4408.2011.00306.x

Singh R (2017) Removal of fluoride from ground water by thermally activated neem (Azadiractica indica) and Peepal (Ficus religiosa) leaves carbon adsorbents. World J Phar Pharm Sci 6:1050-1057. https://doi.org/10.20959/wjpps20177-9491

Tembhurkar AR, Dongre SR (2009) Comparative studies on fluoride removal using natural adsorbents viz Azadirachta indica (neem) and Ficus religiosa (Pipal). J-EN 90:18-23

Publisher's Note Springer Nature remains neutral with regard to jurisdictional claims in published maps and institutional affiliations. 